\title{
The Etiological Study of Fungal Keratitis in a tertiary Hospital of Mandya District, Karnataka, India
}

\author{
Khalid Ahmed $^{1 *}$ and B. Sumangala ${ }^{2}$ \\ ${ }^{1}$ Department of Microbiology, KMCT medical college, Manassery, Calicut 673601. India \\ ${ }^{2}$ Department of Microbiology, MIMS, Mandya-571401, India \\ *Corresponding author
}

\section{Keywords}

Mycotic keratitis, fungal corneal ulcer, fusarium, C shaped markings

\section{Article Info}

Accepted:

15 December 2019

Available Online:

20 January 2020

\section{A B S T R A C T}

Corneal blindness is responsible for 1.5 to 2 million new cases of monocular blindness every year in which ocular trauma and corneal ulceration are significant contributors. Corneal infections of fungal etiology are common in India (19-45\%). Aspergillus (16$53 \%)$ and Fusarium $(10-45 \%)$ species are the common pathogens. Purpose: 1.To Identify and isolate the various fungi causing fungal keratitis. 2. To know the usefulness of Gram stain, $\mathrm{KOH}$ wet mount and fungal culture in identification of fungi. Materials and Methods: After taking written and informed consent taken. Examination by an Ophthalmologist was done. Multiple corneal scrapings were collected using Bard-Parker blade no 15 . Scrapings were collected and used in a sequence first to inoculate on a set of SDA and Blood agar plates, then scrapings were placed on 2 different clean and labelled glass slides for $\mathrm{KOH}$ wet mount, Grams stain. Molds were Identified on the basis of colony morphology such as growth rate, colony texture, color, diffusible pigment , and aerial or vegetative hyphae. Results: Out of 68 study subjects, 18 (26.4\%) were culture positive. 45 males and 23 were females. Mean Age was 40. Fusarium sp was predominant (44.4\%) followed by Aspergills sp (38.9\%). Conclusion: Fungal keratitis being a sight threatening disorder, early clinical suspicion, rational use of laboratory diagnostic procedures for timely mycological diagnosis and therapy at right time are important.

\section{Introduction}

Corneal ulcer is a major public health problem in the developing countries causing prolonged visual impairment and ocular morbidity. ${ }^{1}$

Corneal blindness is responsible for 1.5 to 2 million new cases of monocular blindness every year, in which ocular trauma followed by corneal ulceration are significant contributors. ${ }^{2}$ Corneal infections of fungal etiology are common in India (19-45\%). Aspergillus (16-53\%) and Fusarium (10$45 \%$ ) species are the common pathogens. ${ }^{1}$

But early diagnosis is confounded by similar clinical appearances seen in infections with organisms like Herpes simplex, Nocardia, Actinomyces, Streptomyces, Mycobacteria and Acanthamoeba. ${ }^{3}$ 
The incidence of corneal ulceration in India is reported to be 1130 per million population. ${ }^{4}$

Hence this study is an attempt to study the etiology, clinical features, and diagnosis of fungal corneal ulcer.

The main objectives of this study includes, to Identify and isolate the various fungi causing fungal keratitis. And to know the usefulness of Gram stain, $\mathrm{KOH}$ wet mount and fungal culture in identification of fungi.

In a study by Srinivsan et al, conducted in 1997, 46.8\% had pure fungal infections and $5.1 \%$ had mixed bacterial infections. ${ }^{4}$. In India, a recent study by whitcher JP et al, suggests that approximately $1 \%$ of the population or $\sim 9$ million people will acquire microbial keratitis in 10 years and $50 \%$ of the cases will be fungal. ${ }^{5}$

In another study done by Bharthi et al in South India, fungal etiology was confirmed in $34.4 \%$ cases of corneal ulcers. ${ }^{6}$ The incidence of fungal keratitis was significantly higher in males, in individuals from rural areas and following corneal injury. It has been observed that younger people aged 21-50 years are more often affected by fungal keratitis compared to those above 50 years, who are affected by bacterial ulcers. ${ }^{6}$. In a study done in Hyderabad, India the percentage of fungal corneal ulcers was $38.2 \%$.

\section{Pathogenesis of fungal corneal ulcers}

Fungi are ubiquitous, saphrophytic, or pathogenic organisms. Fungi gain access onto the corneal stroma through a defect in the epithelial barrier. This defect may be due to external trauma, including contact lenses, a compromised ocular surface, or previous surgery. Once in the stroma, they multiply and can cause tissue necrosis and a host inflammatory reaction. Organism can penetrate deep into the stroma and through an intact Descemet's membrane. Once the organisms gain access into the anterior chamber or to the iris and lens, eradication of the organism becomes extremely difficult. This also explains why a conjunctival flap helps control fungal growth. ${ }^{9}$

In a study Thomas $\mathrm{P}$ A et al, to assess characteristic clinical features to be used as a diagnostic aid, it was found that serrated margins, dry texture, raised slough, discolourations other than yellow occurred and satellite lesions, found more frequently in cases of filamentous fungal ulcers than bacteria. ${ }^{10}$

Bhrathi, M. J., R. Ramakrishnan et al in the year 2003 examined 3183 cases of corneal ulcer. The predominant fungal species isolated was Fusarium $\mathrm{sp}(477 ; 42.81 \%)$ followed by Aspergillus sp(286.26\%). Males(712;65.08\%) were more often affected. Ocular trauma $(1009 ; 92.15 \%)$ was a highly significant risk factor. ${ }^{6}$

Sivareddy $\mathrm{P}$, et al in their study on Mycotic Keratitis in Hyderabad, found that out of 600 corneal ulcer cases 36(17.3\%) were of fungal etiology. Out of 36 cases of fungal keratitis, $20(55.5 \%)$ were found in agricultural workers. $^{11}$

Subbannayya Kotigadde, et al in the yar 1992 did a study on Mycotic keratitis in coastal Karnataka noted that out of 295 corneal ulcer cases 67 were positive for fungus, Aspergillussp was most common fungi isolated followed by Candidasp .Females belonging to the age group of 10 to 39 above 60 years showed higher cases than in males of corresponding age, while males in age group of less than 10 years and 40 to 50 years were more in number. Overall it was in females more common (26.87\%) than in males (19.25\%).More no of positive cases noted in October (35.71\%), June (29.62\%) and January 
(28.13\%). Out of 67 cases 31 were house wives and 15 cases were from agricultural activity. $^{12}$

Another study by MJ Bharathi, R Ramakrishnan (2002) did a study to identify the specific microbial pathogens responsible for corneal ulceration in South India, where it was seen that in 18 months study, fungal keratitis was seen in $30(1.85 \%)$ patients out of 1126 positive cses. ${ }^{13}$

A study was done by Yogeshbhadange et al in 2013 on the role of liquid culture media in the laboratory diagnosis of microbial keratitis, found that it increases the chance of isolation. It was recommended that both solid and liquid media in the lab diagnosis of non viral keratits. $^{14}$. Coster examined 67 cases of suppurative keratitis in London in 1981, reported $3 \%$ due to fungi ( 2 cases). ${ }^{15}$

\section{Materials and methods}

\section{Source of data}

Study design: Prospective study.

Stud period: 1 year from June 2013 to May 2014.

Sample size: Consented subjects, who are attending ophthalmology OPD and clinically suspected to have fungal keratitis.

Sampling method: Purposive sampling.

\section{Inclusion criteria}

All patients who presented to Ophthalmology OPD of Mandya Institute Of Medical Sciences, and suspected with clinical diagnosis of fungal keratitis and agreed to participate in the study were included.

\section{Exclusion criteria}

- Patients who refuse to give consent.

- Patients who were clinically suspected to have bacterial, viral, protozoal and non infective etiology were excluded.

\section{Method of collection of data}

Written informed Consent was obtained. Clinical history was noted and detailed examination with slit lamp biomicroscope by an Ophthalmologist was done. After removal of debris or discharge in the vicinity, Corneal scrapings were collected using sterile BardParker blade no. $15{ }^{16}$

Multiple scraping of the affected part of cornea, ulcer margins and bed was done under aseptic precaution with topical anaesthesia (4\% lignocaine hydrochloride) with the aid of a slit-lamp, used in a sequence first to inoculate on a set of SDA with Chloramphenicol plates and a set of Blood agar plates, then scrapings were placed on 2 different clean and labelled glass slides for $\mathrm{KOH}$ wet mount, Grams stain respectively.

\section{Potassium Hydroxide (KOH) Wet Preparation 16,17,18}

Corneal scraping sample was placed on a first labelled glass slide and a drop of $10 \% \mathrm{KOH}$ is put on it. Cover slip is placed and the preparation warmed for better digestion of tissue material. Presence of branching refractile fungal filaments was observed and findings were noted.

\section{Gram Stain 16,19,20}

Scrapings on the second labeled glass slide were spread to make a smear and fixed with 95\% methanol. Gram stain was done, Gram positive fungal filaments, septate or aseptate, branching or non-branching were noted. Gram 
positive budding yeast cells with pseudohyphae if was found it was noted. Culture 16,19,20,21

Specimens were inoculated on the surface of culture media ,making multiple "C" shaped marks without cutting the agar. Corneal scrapings were inoculated onto a set of SDA with Chloramphenicol and on a set of Blood agar plates, under strict aseptic precautions. One each set was incubated at $37^{\circ} \mathrm{C}$ and another at room temperature. Culture media were inspected daily, and the growth was noted and standard procedures for description of colony morphology followed for identification of filamentous fungi. Molds were Identified on the basis of standard description of colony morphology such as growth rate, color, colony texture, and aerial or vegetative hyphae with diffusible pigment. Slide cultures was done on Potato Dextrose Agar for sporulation pattern

\section{For identification of Yeasts: $:^{16,19,20,21}$}

Growth pattern on SDA with Chloramphenicol and BA plate was observed and further speciation done by Germ tube test, pattern of sporulation on Cornmeal agar, and Urease production test. An isolate is more likely to be considered significant if,

1. Confluent growth at the site of inoculation on any one medium.

2. Correlation of Smear results with growth on one medium.

3. The same organism, was grown on more than one media.

Bacterial contamination of Saboraud's dextrose agar was avoided by incorporating chloramphenicol in a concentration of 50 $\mathrm{ug} / \mathrm{ml}$. The majority of fungi causing keratitis were detected on SDA within 72 hours. Aspergillus and Fusarium species showed growth on SDA within 48 hours. Culture media were observed for at least 2 weeks before reporting them as negative. ${ }^{22}$

Plan for data analysis

The data was entered in Microsoft Excel sheet and analysed using SPSS software version 15. Data was analysed using the descriptive statistics, 'chi-square' test and other statistical tests as required.

\section{Results and Discussion}

Sixty Eight patients attending Ophthalmology OPD who were suspected clinically of fungal keratitis were studied in the Department of Microbiology in Mandya Institute of Medical Sciences, Mandya. Observations were made as follows:

Table.3 stated that age distribution in the present study subjects ranged from 3 to 75 years. Maximum number were seen in 26 to 40 years age group. Mean Age was 40.42. Out of 68 study subjects $45(66.1 \%)$ were males and $23(33.9 \%)$ were females. Male to female ratio was $1.95: 1$. Among males majority 15 (78.9\%) were 41-55 age group followed by $13(61.9 \%)$ in $26-40$ age group. Among females majority $8(38.1 \%)$ were from age group 26-40 years.

Table. 5 shows that among 68 cases, Gram stain was positive for fungal elements in 17 cases, out of which $16(94.1 \%)$ were confirmed by culture. Gram stain was negative in 51 cases, among which 2 showed positive fungal culture. Sensitivity of the Gram stain was found to be $88.9 \%$. Specificity Gram stain was found to be 98\%. Positive predictive value was $94.1 \%$. Negative predictive value was $96 \%$.

Table. 6 shows that out of 68 cases, $\mathrm{KOH}$ wet mount was positive for fungal elements in 14 cases, all showed growth. Out of 54 cases negative by $\mathrm{KOH}$ wet mount 4 cases showed fungal growth. Sensitivity of $\mathrm{KOH}$ was found to be $77.8 \%$. Specificity of $\mathrm{KOH}$ was found 
to be $100 \%$. Positive predictive value was $100 \%$. Negative predictive value was $92.5 \%$.

Table. 7 indicates Among 68 cases studied 18 (26.4\%) were culture positive, out of which 16 showed single growth and 2 cases showed mixed growth with bacteria. Bacteria were isolated from $21(30.9 \%)$ cases, there was no growth in $31(45.5 \%)$ cases. Among the bacterial flora Gram positive cocci were isolated from 18 cases, out of which predominant flora was CONS and 3 were Pseudomonas .Fungal growth was found in 16 cases singly and 2 with mixed bacterial growth .

Table. 8 shows that this study among the fungi isolated Fusarium sp was predominant (44.4) followed by Aspergillus sp (38.9). Cladosporium was isolated from $11 \%$ of cases and Candida albicans was isolated from 5.6\% cases only.

Table.1 Frequency of various fungi responsible for keratomycoses worldwide ${ }^{8}$

\begin{tabular}{|l|l|l|l|l|l|}
\hline Fungi & Hyderabad & $\begin{array}{l}\text { New } \\
\text { Delhi }\end{array}$ & Singapore & Ghana & Florida \\
\hline Fusarium & $38 \%$ & $11 \%$ & $52 \%$ & $42 \%$ & $52 \%$ \\
\hline Aspergillus & $30 \%$ & $40 \%$ & $17 \%$ & $17 \%$ & $4 \%$ \\
\hline Penicillium & - & $7 \%$ & $3 \%$ & 0 & $2 \%$ \\
\hline Curvularia & $4 \%$ & $7 \%$ & $3 \%$ & $1 \%$ & $9 \%$ \\
\hline $\begin{array}{l}\text { Other } \\
\text { dematiaceae }\end{array}$ & $16 \%$ & $17 \%$ & 0 & $6 \%$ & $10 \%$ \\
\hline Candida & 0 & $1 \%$ & $10 \%$ & $1 \%$ & $8 \%$ \\
\hline Total no of cases & 557 & 211 & 29 & 109 & 240 \\
\hline
\end{tabular}

Table.2 Difference between filamentous fungi and yeast fungal keratitis

\section{Filamentous fungi \\ Occurs more frequently in young people(occupational and outdoor activity), usually no predisposing factor}

Involved area can be localized and is often elevated; epithelial defect may or may not be present; Often has feathery edges and satellite lesions.

\section{Yeasts}

Usually occurs in an immunocompromized host, pre existing corneal disease or steroid treatment.

Usually more focal, elevated and suppurative, resembling bacterial keratitis

Edges not feathery and satellitism not usually seen. 
Table.3 Age and Sex Distribution of Patients

\begin{tabular}{|l|c|c|c|}
\hline $\begin{array}{l}\text { Age group in } \\
\text { years }\end{array}$ & Male (\%) & Female (\%) & Total (\%) \\
\hline$\leq \mathbf{1 0}$ & $1(50)$ & $1(50)$ & $2(2.9)$ \\
\hline $\mathbf{1 1 - 2 5}$ & $6(46.2)$ & $7(53.8)$ & $13(19.1)$ \\
\hline $\mathbf{2 6 - 4 0}$ & $13(61.9)$ & $8(38.1)$ & $21(30.9)$ \\
\hline $\mathbf{4 1 - 5 5}$ & $15(78.9)$ & $4(21.1)$ & $19(27.9)$ \\
\hline $\mathbf{5 6 - 7 0}$ & $7(70)$ & $3(30)$ & $10(14.7)$ \\
\hline$\geq 71$ & $3(100)$ & 0 & $3(4.4)$ \\
\hline Total & $45(66.1)$ & $23(33.9)$ & $68(100)$ \\
\hline
\end{tabular}

Table.4 Location of the Ulcer

\begin{tabular}{|l|l|}
\hline Location & Frequency $(\%)$ \\
\hline Central & $45(66.1)$ \\
\hline Peripheral & $23(33.9)$ \\
\hline Total & $68(100)$ \\
\hline
\end{tabular}

Majority 45(66.1\%)of the cases presented with Central ulcer in our study

Table.5 Comparison of Gram stain and Fungal culture

\begin{tabular}{|l|c|c|c|}
\hline Gram staining & Number(68) & Culture Positive(\%) & Culture Negative \\
\hline $\begin{array}{l}\text { Positive for fungal } \\
\text { filaments }\end{array}$ & 17 & $16(88.88)$ & 1 \\
\hline $\begin{array}{l}\text { Negative for fungal } \\
\text { filaments }\end{array}$ & 51 & $2(11.11)$ & 49 \\
\hline
\end{tabular}

Table.6 Comparison of $\mathrm{KOH}$ mount and Fungal culture

\begin{tabular}{|l|c|c|c|}
\hline KOH wet mount & $\begin{array}{c}\text { Number } \\
(\mathbf{6 8})\end{array}$ & $\begin{array}{c}\text { Culture Positive } \\
(\boldsymbol{\%})\end{array}$ & Culture negative \\
\hline $\begin{array}{l}\text { Positive for fungal } \\
\text { filaments }\end{array}$ & 14 & $14(77.77)$ & 0 \\
\hline $\begin{array}{l}\text { Negative for fungal } \\
\text { filaments }\end{array}$ & 54 & $4(22.22)$ & 50 \\
\hline
\end{tabular}


Table.07 Microbial Flora Isolated

\begin{tabular}{|l|l|l|l|}
\hline Culture results & $\begin{array}{l}\text { Male } \\
(\%)\end{array}$ & $\begin{array}{l}\text { Female } \\
(\%)\end{array}$ & Total \\
\hline Pseudomonas aeruginosa & $3(100)$ & 0 & 3 \\
\hline CONS & $5(55.5)$ & $4(44.5)$ & 9 \\
\hline Staphylococcus aureus & $1(25)$ & $3(75)$ & 4 \\
\hline Fungi & $12(75)$ & $4(25)$ & 16 \\
\hline Mixed Bacterial and Fungal & $1(50)$ & $1(50)$ & 2 \\
\hline Growth & $2(66)$ & $1(33)$ & 3 \\
\hline Streptococcus pneumonia & $21(67)$ & $10(33)$ & 31 \\
\hline No Growth & $45(66.1)$ & $23(33.9)$ & $68(100)$ \\
\hline Total & & & \\
\hline
\end{tabular}

Table.8 Percentage Distribution of Fungal Isolates

\begin{tabular}{|l|l|}
\hline Fungus Isolated & Frequency $(\%)$ \\
\hline Fusarium Sp & $8(44.44)$ \\
\hline Aspergillus Sp & $7(38.89)$ \\
\hline Cladosporium & $2(11.11)$ \\
\hline Candida albicans & $1(5.56)$ \\
\hline Total & $18(100)$ \\
\hline
\end{tabular}


Int.J.Curr.Microbiol.App.Sci (2020) 9(1): 1473-1484

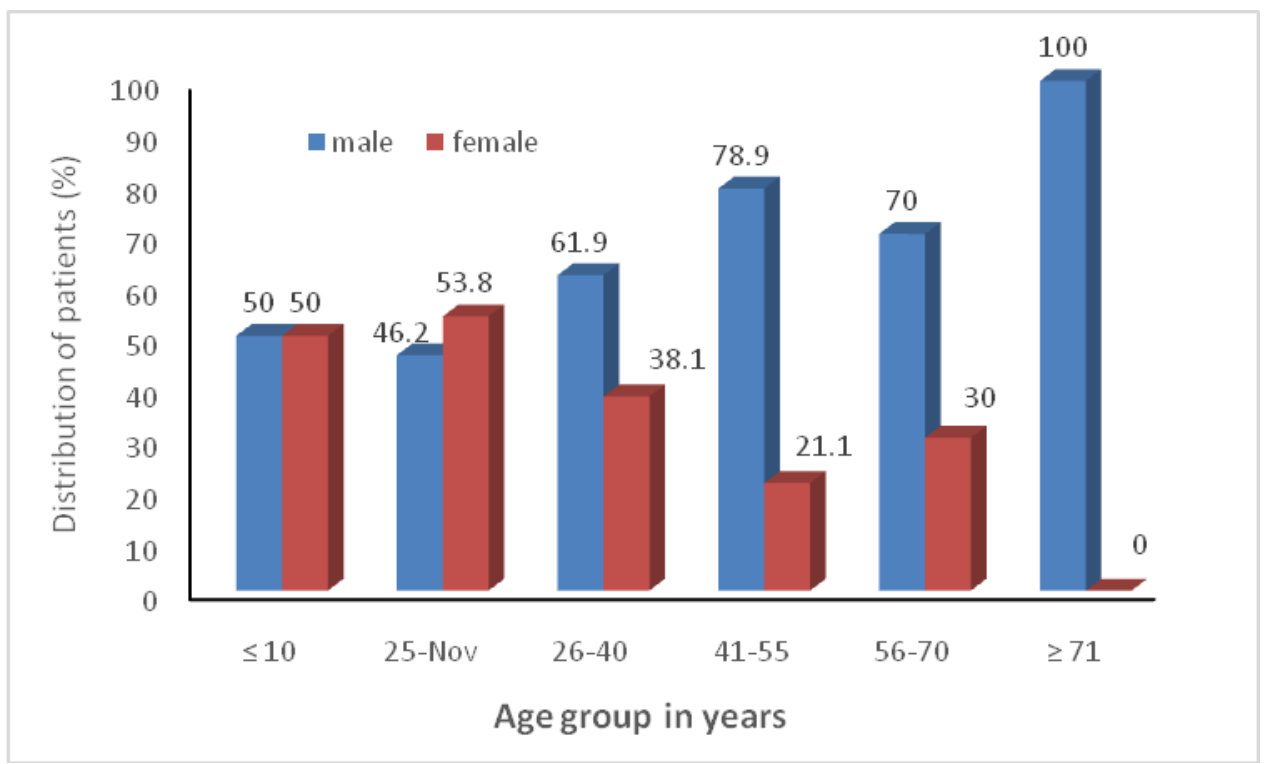

Graph.1 Age wise distribution of patients

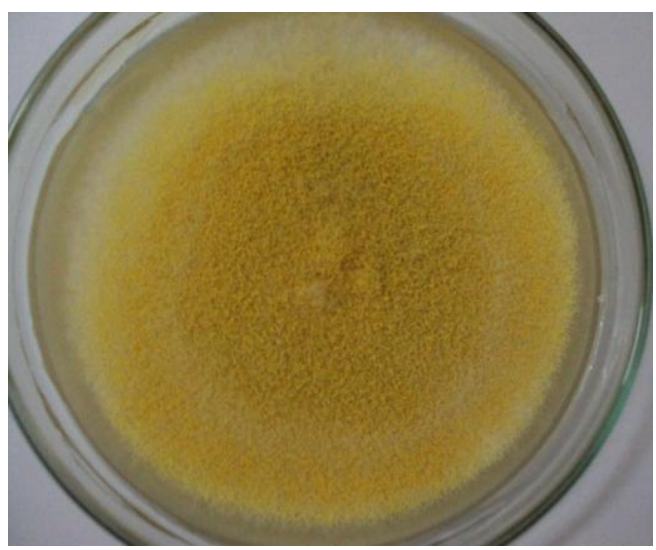

Fig 1 Aspergillus Flavus

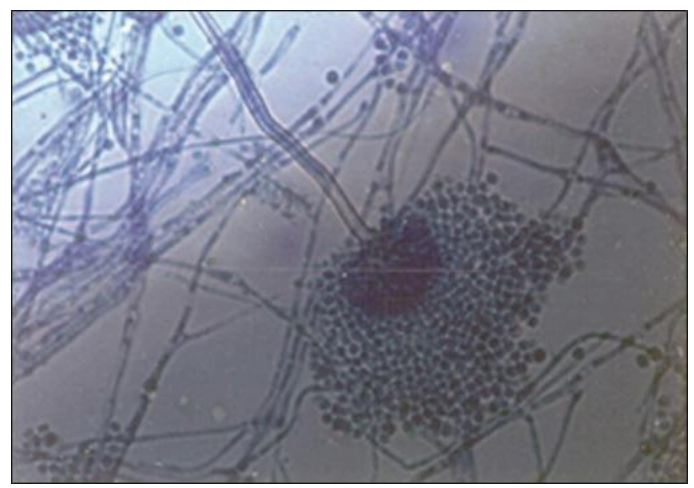

Fig.2 Lactophenol cotton blue preparation showing fungal conidia and the septate hyphae 


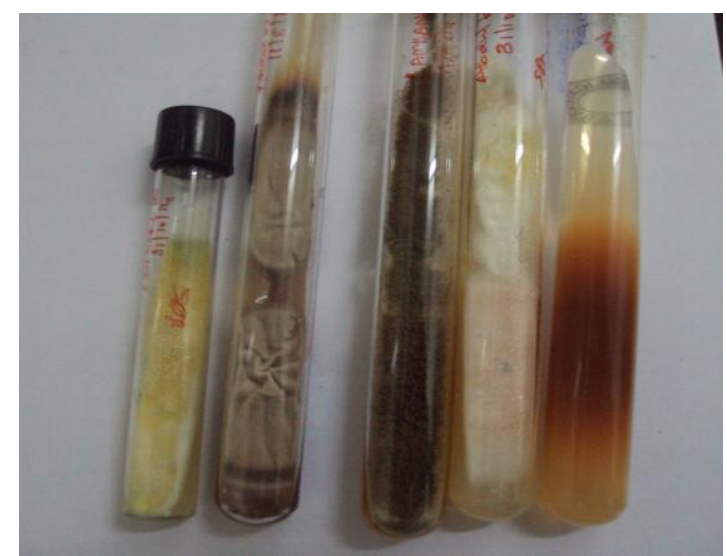

Fig.3 Various Fungi Isolated from the cases

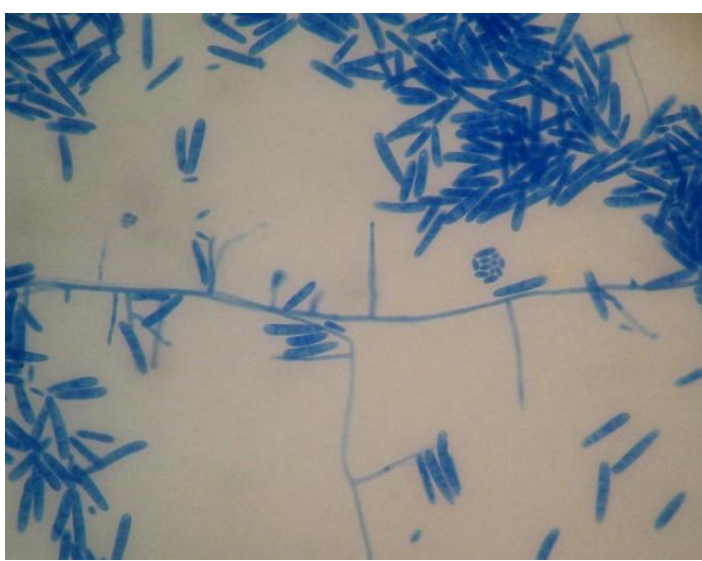

Fig.4 Fusarium species on LPCB mount

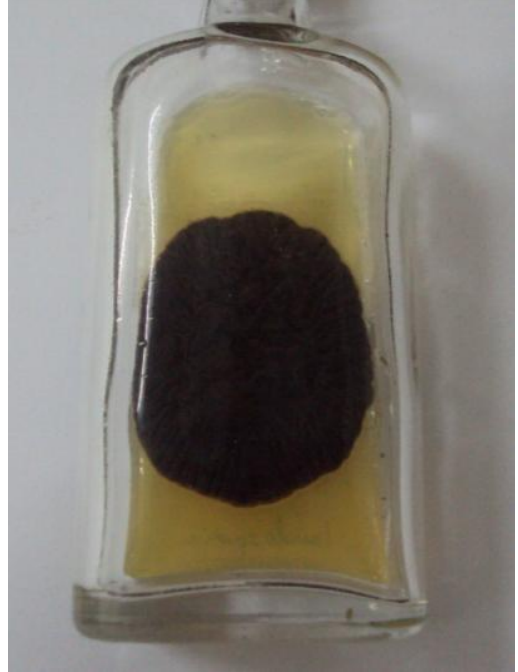

Fig.5 Cladosporium

In the present study the commonest age group affected was between 26-40 years, it correlates well with the age range involved in the most active period of life and increased vulnerability to injury during outdoor activities. This has a considerable socioeconomic impact because this age group people are bread winners of the family. In the present study $26.4 \%$ cases were culture positive which is not in agreement with other studies. 
Lower rate of isolation may be attributable to partially treated ulcers before presentation and inadequate specimen obtained from small ulcers, non-infectious causes \& geographical distribution of study group. Some of the culture negative cases might represent true sterile ulcers. In the present study, fungal elements were seen in Gram stain in $88.9 \%$ of culture positive cases correlating with Kamlesh et al. ${ }^{23}$

In the present study fungal elements were seen in $\mathrm{KOH}$ wet mount in $77.8 \%$ of culture positive cases correlating with Deshpande et $a l .{ }^{24} 22.2 \%$ culture positive cases were negative by $\mathrm{KOH}$ mount. Compared to $\mathrm{KOH}$, by Gram stain, more number of cases were recognised.

Sharma et al opined that $\mathrm{KOH}$ positive cases could be considered as fungal ulcers irrespective of the fungal culture positivity. ${ }^{25}$ The probable cause of this may be due to the presence of non-viable fungal elements at the time of culture Variation in positivity may be attributed to inadequate material available and also to the fact organism are not present in all parts of the lesion. Culture is more sensitive than $\mathrm{KOH}$ mount. Clinical history, clinical examination, different staining methods, $\mathrm{KOH}$ mount, all contribute and support the diagnosis of fungal keratitis by fungal culture as indicated by several studies. No single test is reliable for definitive diagnosis.

In the present study, bacteria were isolated is $27.9 \%$ \& is correlating with Khanal et al.$^{26}$ Fungi isolated $23.5 \%$ comparable to Kamlesh et $a .^{23}$ Fusarium sp $44.5 \%$ was the commonest fungal isolate in the present study which is comparable to Srinivasan et al. $^{4}$ Aspergillus sp was second most common $(38.5 \%)$ isolate. Non pigmented Fungal keratitis $(83.2 \%)$ was more common than pigmented keratitis in the present study which correlates with Sengupta et al (68.7\%).
Among the Dematiacious fungi, only Cladosporium was isolated in $11.1 \%$ cases. Yeasts were isolated in $5.5 \%$ cases. Preponderance to different fungi are found in different geographical area depending on the climatic conditions and natural environment.

Fungal keratitis being a sight threatening disorder, early clinical suspicion, rational use of laboratory diagnostic procedures for timely mycological diagnosis and appropriate therapy at right time are important to achieve optimum treatment outcome.

Microbiological work up goes a long way in facilitating specific therapy in fungal corneal ulcers. $\mathrm{KOH}$ mounts were in agreement with fungal culture in $77.8 \%$ of cases and so it can be used as a quick and reliable method to find out fungal etiology of corneal ulcers and treatment can be started immediately without waiting for the culture reports to arrive.

Combination of direct microscopy by Gram stain and $\mathrm{KOH}$ preparation with culture gives better yield of microorganisms than either method alone. . Fusarium is known to pose therapeutic challenge so speciation of fungi is mandatory. Pigmented keratitis cannot be established in all the cases. A definitive diagnosis by microbiological study is a must. Increasing incidence and poor outcome of pigmented keratitis is reported by Sabyajit Sengupta et al .

\section{References}

1. Guidelines for the Management of Corneal Ulcer at Primary, Secondary and Tertiary Care health facilities in the South- East Asia Region, World Health Organization Bulletin ,Geneva,2004; 6-8

2. John P Whitcher, M. Srinivasan, Madan P. Upadhyay, Corneal blindness: a Global Perspective, World Health Organization Bulletin, 2001; 79(3):216-217

3. Robert C. Arffa, Grayson's Diseases of the Cornea, 4th edition, Mosby Publications; 
1997:257-269

4. Srinivasan M, Gonzales CA, George C et al. Epidemiology and etiological diagnosis of corneal ulceration in Madurai, South India. Br J Ophthalmol 1997; 81: 965-971

5. Whitcher JP, Srinivasan M; Corneal ulceration in the developing world- a silent epidemic. Br J Ophthalmol 1997; 81: 622623.

6. Bharathi MJ, Ramakrishnan R, Vasu S, Meenakshi R, Palaniappan R. Epidemiological characteristics and laboratory diagnosis of fungal keratitis. A three-year study. Indian J Ophthalmol 2003; 51: 315-321

7. Gopinathan U, Sharma S, Garg P, Rao GN. Review of Epidemiological features, microbiological diagnosis and treatment outcome of microbial keratitis. Experience over a decade. Indian J Ophthalmol 2009; 57: 273-279

8. Marlene Durand, Fungal Keratitis, Conjunctivitis and Canaliculitis: Mycology. In: Foster CS, Azar DT, Dohlman CH. Smolin and Thoft's, The Cornea, Scientific Foundation and Clinical Practice, LippinCott Williams \& Wilkins Publishers, 4th Edition, 397-404.

9. Eduardo C Alfonso, Robert HR Jr, Darlene Miller. Fungal Keratitis. In: Jay $\mathrm{H}$ Krachmer, Mark J Mannis, Edward J Holland. Cornea; Elsevier Mosby Publication 1997; Vol 1,2nd Edition, 1101-1110

10. Thomas PA, Leck AK, Myatt M. Characteristics Clinical Features as an aid to Diagnosis of Suppurative keratitis caused by Filamentous fungi. $\mathrm{Br} \quad \mathrm{J}$ Ophthalmol 2005; 89: 1554-58.

11. Reddy PS, Satyendran OM, Satapathy M, Vijaya HK, Reddy PR. Mycotic Keratitis. Indian J Ophthalmol 1972; 20: 101-108.

12.SubbannayyaKotigadde et al. Mycotickeratitis : A Study in coastal Karnataka. Indian J Ophthalmol 1992; 40(1): 31-33
13. Bharathi MJ et al. etiological diagnoses of microbial keratitis in South India; Astudy of 1618cases.Indian journal of Medical microbiology 2002; 20:19-24.

14. Yogesh Bhadange, et al. Role of Liquid Culture Media in the Laboratory Diagnosis of Microbial Keratitis.American J Ophthalmol 2013

15. Coster D. J., Paul R. Badenoch. 1987 "Host, microbial and pharmacological factors affecting the outcome of suppurative keratitis". Br. J. Ophthalmol., 71: 96-101

16. Sharma S, Athmanathan S. Diagnostic Procedures in Infectious Keratitis. In: Nema HV, Nema N, Diagnostic Procedures in Ophthalmology, $2^{\text {nd }}$ edition, aypee Brothers Medical Publishers Ltd., 2009, 316-332

17.Diseases of the Cornea In: Ramanjit Sihota, Radhika Tandon, Parson's diseases of the eye, $20^{\text {th }}$ edition, Elsevier Publications 2007, 181-209.

18. Wilson LA, Sexton RR. Laboratory diagnosis in fungal keratitis. Am $J$ Ophthalmol; 66: 646-53

19. Alfonso CE, Forster RK, Garg P, Sharma S. Fungal Infections In : In: Foster CS, Azar DT, Dohlman CH. Smolin and Thoft's , The Cornea, Scientific Foundation and Clinical Practice, LippinCott Williams \& Wilkins Publishers, 4th Edition,

20.Textbook of Medical Mycology, Dr Jagdish Chander, Mehta Publishers, $1^{\text {st }}$ Edition, 215-275.

21.Sridhar MS, Sharma S, Gopinathan U, Rao GN. Anterior chamber tap: diagnostic and therapeutic indications in the management of ocular infections, Cornea 2002; 21(7): 712-722.

22.Netto MV, Mohan RR, Ambrosio R Jr, et al. Wound Healing in the cornea: a review of refractive surgery complications and new prospects for therapy. Cornea 2005; 
24: 509-22

23. Kamlesh V. Behari., Srivatsav. "Various factors in etiopathogenesis of galloping corneal ulcer and their response to therapy". Ind. J. Ophthalmol1983 ;31:692-697

24.Deshpande S.D., G. V. Koppikar. 1999 "A Study of Mycotic Keratitis in Mumbai". Indian J. Pathol. Microbiol., 42(1) : 81-87

25.Sharma S, Silverberg M, Mehta P, Gopinathan U, Agarwal V, Naduvilath TJ. Early diagnosis of Mycotic Keratitis: predictive value of pota ssium hydroxide preparation. Indian J Ophthalmol; 46: 3135

26. Khanal B., K. R. Kaini, et al "Microbial keratitis in BPKIHS-A preliminary study". Proceedings of XXIII National Congress of Indian Association of Medical Microbiologists 1999; 18-21

27.SabyasachiSengupta, et al. Comparative study on the incidence and outcomes of pigmented versus non pigmented keratomycosis. Indian J Ophthalmol 2011; 59(4): 291-296

\section{How to cite this article:}

Khalid Ahmed and Sumangala, B. 2020. The Etiological Study of Fungal Keratitis in a tertiary Hospital of Mandya District, Karnataka, India. Int.J.Curr.Microbiol.App.Sci. 9(01): 1473-1484. doi: https://doi.org/10.20546/ijcmas.2020.901.164 